https://doi.org/10.52449/1857-4114.2020.35-1.08

CZU: 371.3:004

\title{
DESIGN FOR ONLINE TEACHING AND LEARNING IN TNE CONTEXT OF DIGITAL EDUCATION
}

\author{
Sîrghi Serghei ${ }^{1}$ \\ Sîrghi Angela ${ }^{2}$ \\ ${ }^{1}$ State University of Physical Education and Sport, Chișinău, Republic of Moldova \\ ${ }^{2}$ Institute of Continuing Education, Chișinău, Republic of Moldova
}

\begin{abstract}
We live in the XXI century, the century of new technologies. ICT has had a huge positive affect upon the way in which education has evolved and become far easier for the world to access. Education cannot continue any more to work by old methods based on class-lesson system, where the teacher stands before the class and presents the material the students are to learn. To improve the process of teaching and learning new methods based on ICT should be used.

The importance of using online learning in the context of digital education for the development of knowledge, skills and competences in the contemporary educational process is reported in the article. Great attention is focused on the basic concepts of distance learning and mixed learning. It is proposed a model of planning online teaching and learning activities and recommendations at the level of the teaching staff.
\end{abstract}

Keywords: online learning, educational platforms, digital applications, teaching, learning, evaluation, skills.

\section{Introduction}

The twenty-first century is the century of digitalization and information technologies are changing all sectors, including education. Nowadays, we are witnessing several approaches of the educational process both in the country and abroad, mentioning the importance and the need to meet the population's requirements for an accessible and qualitative education by integrating scientific-technical achievements. The reform of the scientific sphere and the stimulation of innovative activity are the key sources of stable economic growth and they are directly associated with the introduction of ICT (also distance learning or distance education) into the academic process. As a result of the implementation of ICT in education, we attest a large number of digital resources that are useful in the educational process and contribute to increasing the performance of the learning and teaching process. In this context, the teacher's role is changing rapidly. The twenty-first century teachers have to inspire and guide students, increase student's employability options, develop digital citizenships and promote "human" skills [7].

Basic Concepts: Distance Learning, Blended Learning

Distance Education is not necessarily a practice which has been recently evolving. The history of distance education even dates way back to the 1800s. In earlier times, correspondence between the student and the teacher took place via post mail. Nowadays, the world-wide-web has revolutionized distance education through various tools and platforms for online communication and learning. Distance learning means planned and organised teaching and learning where 
students are separated from teachers or facilitators in time and space. Therefore, distance education does not include face-toface sessions [8].

Nowadays, the term "blended learning" and "hybrid learning" are currently often used by researchers and practitioners. Blended learning includes all types of education that include some aspect of face-to-face learning and online learning [3].

Blended learning is also used to describe the combination of different training methods, pedagogical approaches or technologies, although they do not fully correspond to the definition of blended learning. Thus, blended learning is characterized by the fact that it includes both online learning and face-to-face elements.

How to combine Face-to-Face and Online Learning in a Blended Learning

Face-to-face (F2F) sessions and online learning can be combined in various ways. We present some examples that include didactic implications:

1: F2F session in the middle of the course, online learning as preparation and follow-up for complex activities in F2F sessions;

2: F2F session at the start of the course, explanation of complex tasks, explanation of the online learning environment;

3: F2F session at the end of the course, collecting feedback, presenting results, reflection;

4: F2F session at the start to explain a task at the start, F2F session in the middle with formative feedback to the task;

5: F2F session to explain a task at the start, F2F session of an exam at the end of the course;

6: F2F session to work on a complex task in the middle of the course, F2F session at the end for an exam, feedback, reflection.

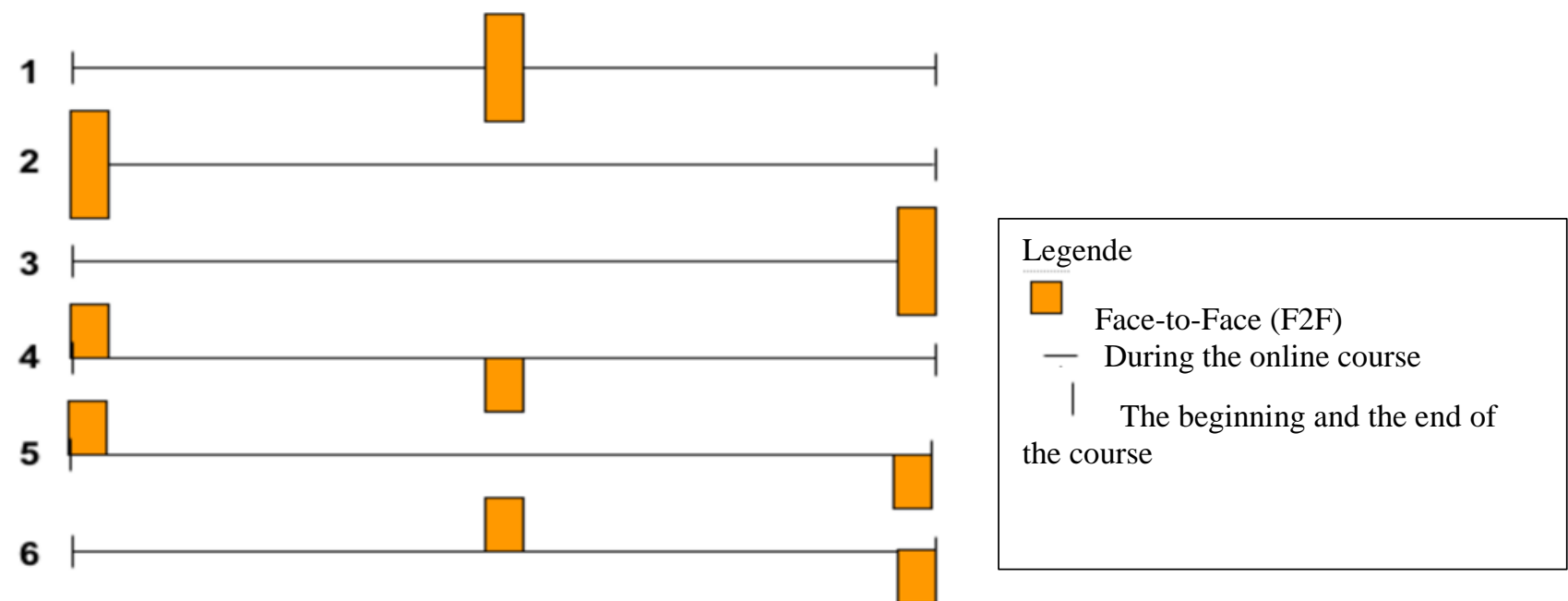

Fig. 1. Combining face-to-face learning (F2F) and online learning (by Baumgartner, 2019)

\section{Stages of Online Learning And Teaching \\ For online learning to be successful,} participants need to be supported through a structured development process. The " fivestage-model " (by Gilly Salmon online learning model) provides a framework for a structured and dynamic programme of etivities, providing essential help and development to participants at each stage as they become more experienced in online learning [5].

In online learning, in addition to the basic course, students should also learn how to use 
the e-learning system. Therefore, it is important to provide an e-learning model in which the participant can very quickly explore the system, and also learn how to communicate online.

Step 1: Access and Motivation

E-tivities need to focus on providing explicit motivation and setting individual pace and rhythm; E-tivities need be designed carefully to enable participants access to the online learning platform while participating in relevant and authentic tasks. It is advisable to start the online session with activities that contribute to the creation of the learning community and environment.

Step 2: Socializing

At this stage E-tivities need to focus on enabling participants to relate and collaborate with each other on the received tasks. Etivities should correlate with the traditional activities of the discipline because it provides the important context for learning and makes later knowledge construction easier to achieve.

Step 3: Learning / Research

E-tivities need to be focused on the content; information is transmitted to each other, explained, clarified and provided feedback. The participants learn to communicate and coordinate work among them in order to achieve the set goals. At this stage you can experiment with the structure of groups and group working techniques.

\section{Step 4: Knowledge construction}

At this stage students became familiar with online working and should be able to manage their time and collaborate with each other. It is recommended to avoid specifying in advance the exact tasks, giving participants the opportunity to state their own point of view, arguing and giving examples from real contexts.

Step 5: Development

Create E-tivities to evaluate the formed knowledge, giving participants the opportunity to demonstrate the ability to work with the content and to make judgements on the experience and the knowledge surfaced and built their own ideas. Encourage metacognitive awareness by answering questions like: How did you arrive at that position? Or which is better and why? [6].

In order to implement successfully online learning in the context of blended learning, it is important to take into account the set objectives and the expected outcomes. The course design is based on learning outcomes, which include both learning and teaching activities and assessment methods. We also take into account the fact that learning activities lead to a formative and summative evaluation, providing students with feedback and evaluation [4]. Thus, the teaching, learning and evaluation activities must be aligned according to the scheme:

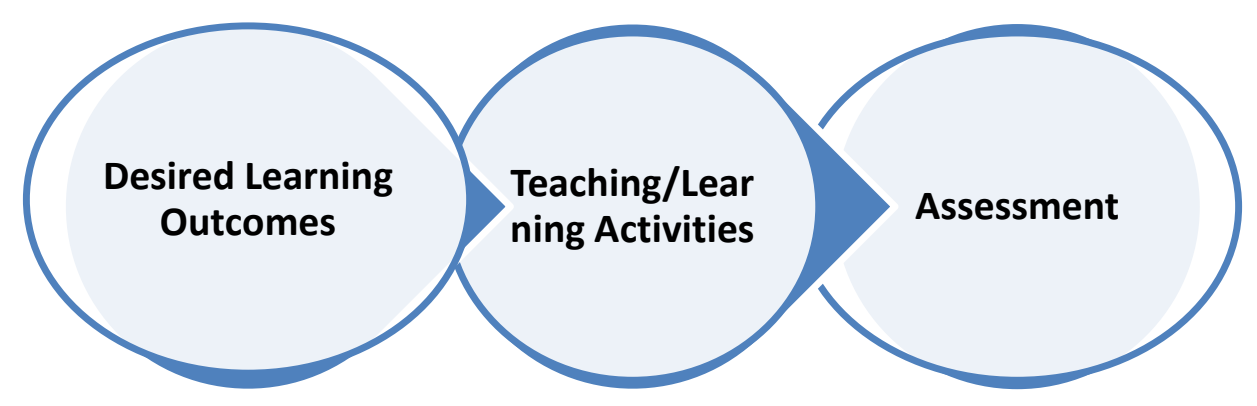

Fig. 2. Alignment for online learning / teaching / evaluation activities 


\section{Basic Online Learning Competences}

Before starting disciplinary content and learning activities, it is important to acknowledge that students have basic digital competences regarding learning online. For example:

- Identifying and finding online learning input.

- Use digital tools to interact with teachers.

- Use of online platforms and digital tools for their individual learning activities.

- Use digital tools to communicate and work in an online group.

- The ability to establish meaningful relationships in an online learning community.

Choosing Digital Tools and Educational Platforms

For the implementation of the online course, it is necessary to choose the right and appropriate digital tools and educational platforms. It is recommended to follow 3 steps for reflection to evaluate which tool/platform is most suitable to reach the learning outcome.

Step 1: Learning Outcomes - which Learning and Teaching Style?

It is necessary to find out which kind of learning and teaching type the learning outcomes are referring to.

Step 2: Suitable Learning and Assessment Activities

We need to take a closer look at the planned learning and assessment activities, in order to make the learning outcome "real", not only words.

Step 3: Choosing Digital Tools and Platforms

Today we can see an abundance of digital resources, which can be actively used in the process of training and training both in the classroom and online:

Digital tools: applications, software programs for specific activities or tasks, such as creation of interactive exercises, tests and evaluations, video content, websites, (e.g. Padlet, Google Forms, Kahoot, Quizizz, Zoom, Mintimeter, etc.)
Educational platforms: learning management systems (LMS) (e.g. Moodle, MOOCs, and Adobe Connect), platforms for collaboration (Google classroom, Canvas, Socrative), ePortfolio, social networks (Facebook, Odnoklassniki, Twitter, Instagram etc.) include a rather broad set of functions.

Another alternative might be the digital platforms and tools used by your educational institution as a basic part of the institutional eLearning infrastructure, and as a supplement to online learning and teaching activities can serve online digital tools offered free of charge $[1,2]$.

All at once we must take into account $\mathbf{3}$ Basic Components of Every eLearning Infrastructure:

$\checkmark$ Software: the programs and applications we are using, digital tools and platforms (e.g. Moodle, Kahoot, Facebook, Padlet etc.)

$\checkmark$ The Hardware: the devices we need to use the software, e.g. a laptop, a webcam, a tablet, headphones, a smartphone, etc. It is important to determine which devices the students, involved in the online learning course use, to avoid certain problems and discomfort. Thus, we design the teachinglearning activities being sure that everyone can participate in the course.

$\checkmark$ Internet access: Learning and teaching online is depending on the quality of internet access both for students and teachers.

For a successful online education, the following recommendations are proposed for the teaching staff:

1. Decide how you will organize and conduct distance learning;

2. Plan your activities ahead of time;

3. Determine how you will communicate with students;

4. Start creating learning tasks or study sheets;

5. Consider the challenges you may face;

6. Try to avoid mistakes;

7. Decide which digital programs you will use;

8. Organize online meetings with students; 
9. Promote learning of content transfer (transdisciplinarity);

10. Propose self-testing activities;

11. Monitor the assimilation of knowledge;

12. Formulate opinions about the interest, curiosity, motivation of students;

13. Choose the right learning platforms and digital tools.

\section{Conclusions}

1. Nowadays, education throughout the world is undergoing a process of profound modernization, primarily due to the trends and policies of the use of information and communication technologies means in the preparation, conduct of classes and assessment of knowledge.

2. It is advisable to explore all the opportunities and possibilities of using the computer and the Internet in open, distance learning, which in Moldova, also will have to be fully exploited in order to develop a competitive e-Learning.
3. Teachers involved in teaching through technology support have great freedom in the design and organization of the study process, becoming tutors, mentors, partners and collaborators for their students in the discovery of scientific truth, but also evaluators of the students' performance.

4. The teacher's preparatory work is necessary for efficient results. Thus, the freedom offered to the student is a "two-way road", because if a student is not sufficiently motivated and does not have an adequate will, he can easily abandon this way of learning.

5. Online or technological activity must be attractive and provide intellectual satisfaction; students should get pleasure of well-done work, but also the satisfaction of socialization, "meeting" and communication with peers. It is necessary the information to be varied, the tasks should include different applications, and the interaction with the teacher is appropriate.

\section{References:}

1. Adăscăliței A. (2007). Instruirea asistată de calculator. Iaşi: Editura Polirom. 205 p.

2. Brut M. (2006). Instrumente pentru e - learning: ghidul informatic al profesorului modern. Iaşi: Editura Polirom. 248 p.

3. Charles R. Graham, Curtis J. Bonk (2006). The Handbook of Blended Learning. Global Perspectives, Local Designs, Pfeiffer.

4. Ghirardini B. (2011). Instructional Designer, E - learning methodologies. A guide for designing and developing e - learning courses. Rome, FAO.

\section{Digital references:}

5. https://www.gillysalmon.com/five-stage-model.html

6. https://cyberlearning.ch/2018/10/16/5-stages-by-gilly-salmon/

7. http://reports.weforum.org/future-of-jobs-2018/

8.https://www.igi-global.com/chapter/from-distance-education-to-open-and-distance learning/227916 